\title{
The Physiological Response of Lettuce to Red and Blue Light Dynamics Over Different Photoperiods
}

Giedrè Samuolienė*, Akvilè Viršilè, Jurga Miliauskienè, Perttu J. Haimi, Kristina Laužikè,
Aušra Brazaitytè and Pavelas Duchovskis

Lithuanian Research Centre for Agriculture and Forestry, Institute of Horticulture, Babtai, Lithuania

OPEN ACCESS

Edited by:

Inga Mewis,

Humboldt University of Berlin

Germany

Reviewed by:

Thomas J. Bach,

Université de Strasbourg, France

Qichang Yang,

Chinese Academy of Agricultural

Sciences, China

*Correspondence:

Giedré Samuoliene

giedre.samuoliene@lammc.lt

Specialty section:

This article was submitted to

Plant Metabolism

and Chemodiversity,

a section of the journal

Frontiers in Plant Science

Received: 25 September 2020

Accepted: 28 December 2020

Published: 12 February 2021

Citation:

Samuoliené G, Viršilè A

Miliauskienè J, Haimi PJ, Laužikè K, Brazaitytè A and Duchovskis P (2021)

The Physiological Response

of Lettuce to Red and Blue Light

Dynamics Over Different

Photoperiods.

Front. Plant Sci. 11:610174 doi: $10.3389 / \mathrm{fp} / \mathrm{s} .2020 .610174$
This study aimed to evaluate the effect of dynamic red and blue light parameters on the physiological responses and key metabolites in lettuce and also the subsequent impact of varying light spectra on nutritive value. We explored the metabolic changes in carotenes, xanthophylls, soluble sugars, organic acids, and antioxidants; the response of photosynthetic indices [photosynthetic $(\mathrm{Pr})$ and transpiration $(\mathrm{Tr})$ rates]; and the intracellular to ambient $\mathrm{CO}_{2}$ concentration ratios $\left(C_{i} / C_{a}\right)$ in lettuce (Lactuca sativa $\mathrm{L}$. "Lobjoits Green Cos"). They were cultivated under constant (con) or parabolic (dyn) blue (B, $452 \mathrm{~nm}$ ) and/or red (R, $662 \mathrm{~nm}$ ) light-emitting diode (LED) photosynthetic photon flux densities (PPFDs) at 12, 16, and $20 \mathrm{~h}$ photoperiods, maintaining consistent daily light integrals (DLIs) for each light component in all treatments, at 2.3 and $9.2 \mathrm{~mol} \mathrm{~m} \mathrm{~m}^{-2}$ per day for blue and red light, respectively. The obtained results and principal component analysis (PCA) confirmed a significant impact of the light spectrum, photoperiod, and parabolic profiles of PPFD on the physiological response of lettuce. The $16 \mathrm{~h}$ photoperiod resulted in significantly higher content of xanthophylls (neoxanthin, violaxanthin, lutein, and zeaxanthin) in lettuce leaves under both constant and parabolic blue light treatments (BconRdyn $16 \mathrm{~h}$ and BdynRdyn $16 \mathrm{~h}$, respectively). Lower PPFD levels under a $20 \mathrm{~h}$ photoperiod (BdynRdyn $20 \mathrm{~h}$ ) as well as higher PPFD levels under a $12 \mathrm{~h}$ photoperiod (BdynRdyn $12 \mathrm{~h}$ ) had a pronounced impact on leaf gas exchange indices $\left(\operatorname{Pr}, \operatorname{Tr}, C_{i} / C_{a}\right)$, xanthophylls, soluble sugar contents, and antioxidant properties of lettuce leaves. The parabolic PPFD lighting profile over a $16 \mathrm{~h}$ photoperiod (BdynRdyn $16 \mathrm{~h}$ ) led to a significant decrease in $C_{i} / C_{a}$, which resulted in decreased $\mathrm{Pr}$ and $\mathrm{Tr}$, compared with constant blue or red light treatments with the same photoperiod (BconRdyn and BdynRcon 16 h). Additionally, constant blue lighting produced higher $\alpha+\beta$-carotene and anthocyanin (ARI) content and increased carotenoid to chlorophyll ratio (CRI) but decreased biomass accumulation and antioxidant activity.

Keywords: xanthophylls, carotenes, soluble sugars, organic acids, antioxidant activity, photosynthesis, dynamic light, photoperiod 


\section{INTRODUCTION}

The effects of light on plants are complex, as it controls photosynthesis, plant growth, and developmental processes. Plants generally absorb radiation in the visible electromagnetic spectrum; however, not the entire spectrum of light is beneficial (Hasan et al., 2017). Under controlled environmental conditions, the mixed application of red and blue light-emitting diodes (LEDs) is usually the first choice where plant growth is a priority (Shen et al., 2014; Bantis et al., 2018). Red and blue LEDs can act as a principal light source, with the potential to improve photosynthesis by stimulating the stomatal activity, which can enhance dry mass and yield (Sabzalian et al., 2014). Various studies have demonstrated that controlled amounts or specific spectra of light affect photosynthetic characteristics (Dong et al., 2014; Samuolienè et al., 2020), metabolism (Samuoliené et al., 2013; Lee et al., 2016), and antioxidant properties (Samuolienè et al., 2012; Lekkham et al., 2016). However, these experiments are typically performed in controlled environment chambers with constant irradiance during the day and abrupt transitions between light and dark at dawn and dusk. In natural environments, plants are adapted to diurnal fluctuations in irradiance and light quality, with gradual shifts between light and dark at the beginning and the end of the day. Moreover, the light in controlled environment chambers differs from natural sunlight in several ways, including qualitative spectral and quantitative intensity changes over the course of the day (Annunziata et al., 2017).

The light-dependent reactions of photosynthesis involve electron and proton transfer from water to $\mathrm{NADP}^{+}$to form $\mathrm{NADPH}$, whereas the dark-dependent reactions involve the fixation of $\mathrm{CO}_{2}$ into carbohydrates via the Calvin-Benson cycle, regenerating $\mathrm{ADP}$ and $\mathrm{NADP}^{+}$(Johnson, 2016). Concentrations of $\mathrm{Mg}^{2+}, \mathrm{pH}$, and thioredoxin play a key role in regulating the activity of the Calvin-Benson cycle enzymes, ensuring that the activity of the light-dependent and light-independent reactions are closely coordinated. Pigment molecules (chlorophylls $a$ and $b, \beta$-carotene, zeaxanthin, neoxanthin, violaxanthin, and lutein), located in the thylakoid membrane, absorbing red and blue light, induce the process of photosynthesis. Moderate stress caused by different environmental factors, including light, influences the metabolism of carotenoids (Fanciullino et al., 2014), as some carotenoids play a key role in the dissipation of excess absorbed energy through the xanthophyll cycle. In light-collecting antennae, carotenoids absorb light in the blue and green region, transferring the absorbed energy to the chlorophylls, thus increase photosynthetic efficiency by expanding the range of wavelengths absorbed (Mozzo et al., 2008; García-Plazaola et al., 2012). Furthermore, exposed to excessive radiation, xanthophylls quench the singlet excited state of chlorophyll in photosystem II (Robert et al., 2004). This process, named nonphotochemical quenching, is linked to the xanthophyll cycle (García-Plazaola et al., 2012); preventing photodamage, it allows plants to acclimate to variable levels of light. Additionally, many carotenoids act as antioxidants. For instance, zeaxanthin can protect membrane surfaces from hydrophilic oxidants (Johnson, 2016), Xanthophylls are precursors of abscisic acid, which modulates stress and developmental processes (Chernys and Zeevaart, 2000), and by quenching excited chlorophyll molecules, $\beta$-carotene exerts an effective photoprotective action (Johnson, 2016).

Plants rely on both rapid response and delayed mechanisms to dynamically acclimate to their environment. Immediate and sensitive responses involve redox and ROS, while delayed responses are related to the accumulation of sugars which can reduce photoinhibition and the associated production of ROS in photosynthetic tissues (Fanciullino et al., 2014). The overall parameter intensities from both response types are integrated to realize appropriate long-term acclimation (Dietz, 2015). Sugars, as the end products of photosynthesis (Stein and Granot, 2019), are information-rich signaling molecules involved in the mechanisms that balance carbohydrate supply and usage in growth and storage processes. For instance, glucose coordinates internal sugar signals with external light conditions (Moore et al., 2003). There are several sugar-sensing mechanisms, including sensory systems for hexoses, sucrose, and raffinose, with increasing evidence suggesting that sugar contents are monitored in the plastids (Häusler et al., 2014). Additionally, photosynthesizing cell metabolisms respond quickly to changes in photosynthetic conditions, in particular, light, temperature, or $\mathrm{CO}_{2}$ availability, which in turn depends on the state of stomatal opening (Dietz, 2015). However, contradictory data on the effect of soluble sugars on the synthesis of carotenoids reflect the distinct strategies in the leaves as a function of light influence (Urban and Alphonsout, 2007). The former leads to a benefit of carotenoids to increase protection against photodamage, leading to a loss of carotenoids when senescence is triggered (Fanciullino et al., 2014).

The aim of this study was to evaluate the effect of dynamic red and blue light parameters on lettuce physiological response and metabolite contents and thereby its impact on nutritive value.

\section{MATERIALS AND METHODS}

\section{Growing Conditions}

Lettuce (Lactuca sativa L. cv. "Lobjoits Green Cos") was grown in a growth chamber in peat substrate (Profile 1, JSC Durpeta, Lithuania) ( $\mathrm{pH} 6$, accuracy $\pm 0.01 \mathrm{pH}$ units). The average concentrations of nutrients $\left(\mathrm{mg} \mathrm{L}^{-1}\right)$ in the substrate were as follows: $\mathrm{N}, 110 ; \mathrm{P}_{2} \mathrm{O}_{5}, 50$; and $\mathrm{K}_{2} \mathrm{O}, 160$. The microelements Fe, $\mathrm{Mn}, \mathrm{Cu}, \mathrm{B}, \mathrm{Mo}$, and $\mathrm{Zn}$ were also present. Electrical conductivity (EC) varied between 1.0 and $2.5 \mathrm{mS} \mathrm{cm}^{-1}$ ( $\pm 0.03 \mathrm{~m}$ ). One seed was seeded into a $120 \mathrm{ml}$ vessel, and 28 plants for each treatment were analyzed. Plants were watered as needed. Experiments were performed in a walk-in controlled environment growth chamber $(4 \times 6 \mathrm{~m})$. Day/night temperatures of $+21 / 17 \pm 2{ }^{\circ} \mathrm{C}$ were established, and the relative humidity was maintained at $50-60 \%$.

LED fixtures, consisting of commercially available LEDs with emission wavelengths $(\lambda)$ of blue $(\lambda=452 \mathrm{~nm}$, LedEngin LZ100B200, Osram Sylvania, United States) and red $(\lambda=662 \mathrm{~nm}$, Luxeon Rebel LXM3-PD01-0300, Lumileds, United States), were used for lettuce lighting. Plants grew under constant (con) or parabolic (dyn) blue (B) and/or red (R) LED photosynthetic 
photon flux density (PPFD) at 12, 16, and $20 \mathrm{~h}$ photoperiods, but the same daily light integral (DLI; 2.3 and $9.2 \mathrm{~mol} \mathrm{~m}^{-2}$ per day for B and R) was maintained for each light component in all treatments (Figure 1). PPFD was measured and regulated at the vessel level by using a photometer-radiometer (RF-100, Sonopan, Poland).

\section{Determination of Pigments}

Xanthophylls (neoxanthin, violaxanthin, lutein, and zeaxanthin), carotenes (carotenes $\alpha$ and $\beta$ ), and chlorophylls (chlorophylls $a$ and $b$ ) were extracted using $80 \%$ acetone (1 g of sample ground with liquid $\mathrm{N}_{2}$ and $10 \mathrm{ml}$ of solvent), centrifuged ( $5 \mathrm{~min}$, $4,000 \mathrm{rpm})$, and filtered through a $0.45-\mu \mathrm{m}$ nylon membrane syringe filter (VWR International, United States). The contents of carotenes, xanthophylls, and chlorophylls were evaluated using a Shimadzu HPLC (Japan) instrument equipped with a diode array detector (SPD-M 10A VP) on a YMC Carotenoid column ( $3 \mu \mathrm{m}$ particle size, $150 \times 4.0 \mathrm{~mm}$ ) (YMC, Japan). The mobile phase consisted of A ( $80 \%$ methanol, 20\% water) and B (100\% ethyl acetate). The gradient was as follows: $0 \mathrm{~min} ; 20 \% \mathrm{~B}$, $2.5 \mathrm{~min} ; 22.5 \% \mathrm{~B}, 20-22.5 \mathrm{~min} ; 50 \% \mathrm{~B}, 24-26 \mathrm{~min} ; 80 \% \mathrm{~B}, 31-$ $34 \mathrm{~min} ; 100 \% \mathrm{~B}, 42-47 \mathrm{~min}$; and $20 \% \mathrm{~B}$, flow rate $1 \mathrm{ml} \mathrm{min}-1$ (Edelenbos et al., 2001). The diode array detector was employed at $440 \mathrm{~nm}$, and the absorption spectra of xanthophylls, carotenes, and chlorophylls were identified using an external standard calibration method.

\section{Determination of Sugars}

About $0.5 \mathrm{~g}$ of fresh plant tissue was ground and diluted with deionized $\mathrm{H}_{2} \mathrm{O}$. The extraction was carried out for $4 \mathrm{~h}$ at room temperature with mixing. Samples were centrifuged at $14,000 \mathrm{~g}$ for 15 min. A clean-up step to remove soluble proteins (Brons and Olieman, 1983) was performed prior to the chromatographic analysis. Briefly, $1 \mathrm{ml}$ of the supernatant was mixed with $1 \mathrm{ml}$ $0.01 \%(\mathrm{w} / \mathrm{v})$ ammonium acetate in acetonitrile and incubated for $30 \mathrm{~min}$ at $+4^{\circ} \mathrm{C}$. The samples were centrifuged at $14,000 \mathrm{~g}$ for $15 \mathrm{~min}$ and filtered through a $0.22 \mu \mathrm{m}$ PTPE syringe filter (VWR International, United States). Sugars were analyzed according to $\mathrm{Ma}$ et al. (2014) with modifications. The analyses were performed on a Shimadzu HPLC (Japan) instrument equipped with an evaporative light scattering detector (ELSD). Separation of fructose, glucose, sucrose, and maltose was performed on a Shodex VG-50 4D HPLC column with deionized water (mobile phase A) and acetonitrile (mobile phase B) gradient. The gradient was maintained at $88 \%$ B for $13 \mathrm{~min}$, changed linearly to $70 \% \mathrm{~B}$ in $9 \mathrm{~min}$, kept at $70 \% \mathrm{~B}$ for $1 \mathrm{~min}$, and raised back to $88 \% \mathrm{~B}$ for $2 \mathrm{~min}$, and the column was equilibrated to $88 \% \mathrm{~B}$ for $5 \mathrm{~min}$. The flow rate was $0.8 \mathrm{ml} \mathrm{min}^{-1}$.

\section{Determination of Organic Acids}

Approximately $0.5 \mathrm{~g}$ of fresh plant tissue was homogenized and diluted with deionized $\mathrm{H}_{2} \mathrm{O}(1: 10)(\mathrm{w} / \mathrm{v})$ and heated in a water bath for $30 \mathrm{~min}$ at $+50^{\circ} \mathrm{C}$. The extract was centrifuged at $10,000 \mathrm{rpm}$ for $15 \mathrm{~min}$ and filtered through a $0.22 \mu \mathrm{m}$ PTPE syringe filter (VWR International, United States). Organic acids were analyzed according to Wang et al. (2014) with modifications. The analyses were performed on a Shimadzu HPLC (Japan) instrument equipped with a refractive index detector. Separation of oxalic, oxaloacetic, malic, ascorbic, folic, citric, succinic, and fumaric acids was performed on a C18 column $(4.6 \mathrm{~mm} \times 250 \mathrm{~mm}, 5 \mu \mathrm{m})$ (Nucleodur) with $0.05 \mathrm{M}$ sulfuric acid in deionized water isocratic elution. The flow rate

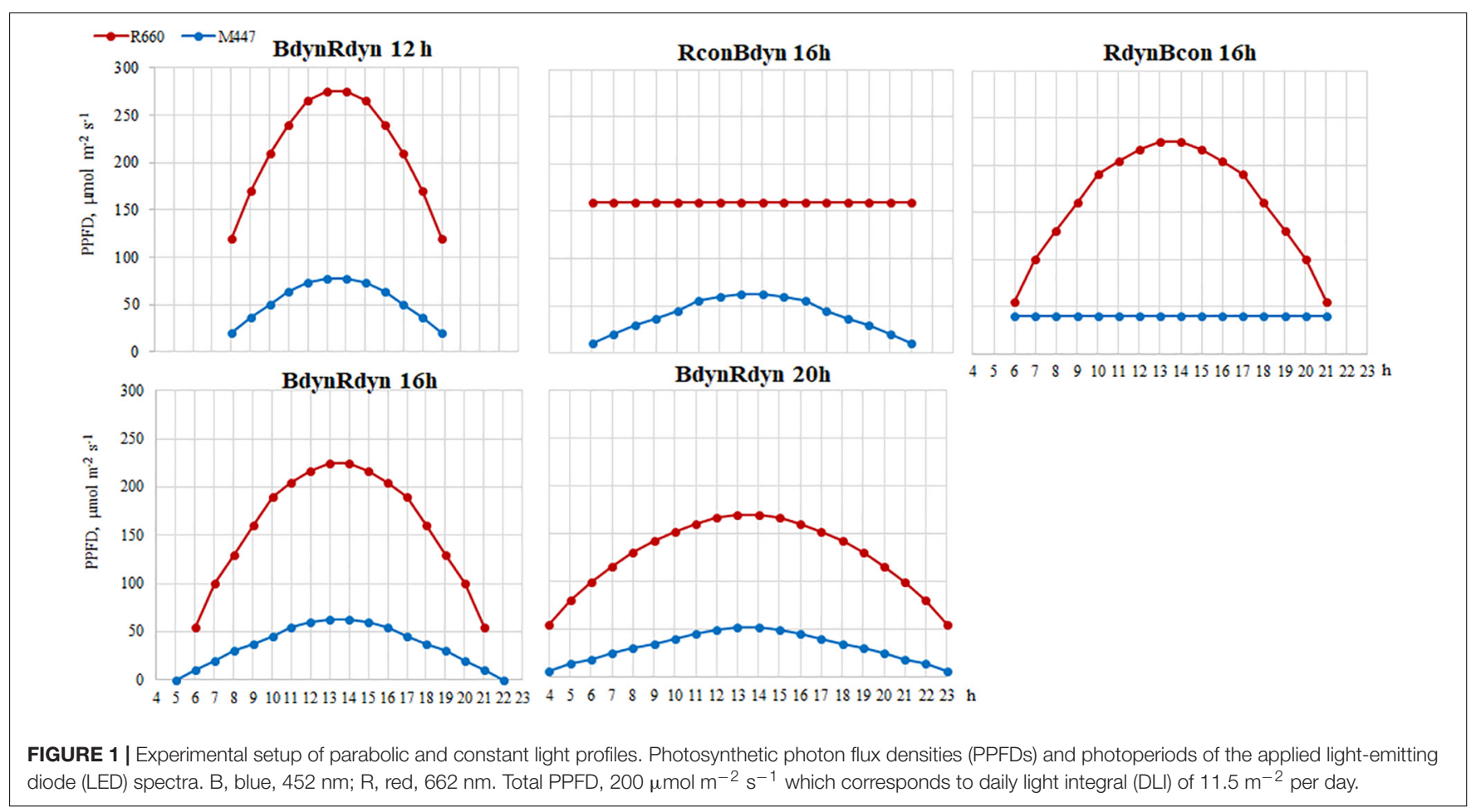


was $0.5 \mathrm{ml} \mathrm{min}{ }^{-1}$. The peak was detected at $210 \mathrm{~nm}$ and identified using an external calibration method.

\section{Determination of Antioxidant Activity}

The antioxidant activity of lettuce leaves was evaluated using DPPH (2-diphenyl-1-picrylhydrazyl), ABTS [2,2'-azino-bis (3ethylbenzothiazoline-6-sulfonic acid) diammonium salt], and an $\mathrm{Fe}^{2+}$ reducing antioxidant power (FRAP) assay (Kraujalyte et al., 2013). Extracts were prepared by grinding the plant material with liquid nitrogen and dilution with $80 \%$ methanol 1:10 (w/v). After $24 \mathrm{~h}$, the extracts were filtered through cellulose filters.

The DPPH free radical scavenging activity was determined by mixing a diluted extract with $0.06 \mathrm{M}$ methanolic DPPH solution and monitoring radical quenching every minute for $16 \mathrm{~min}$ to measure the absorbance at $515 \mathrm{~nm}$ (M501, Camspec, United Kingdom). The results are presented as DPPH free radical scavenging activity, $\mu \mathrm{mol} \mathrm{g}^{-1}$ of fresh plant weight.

The ABTS radical solution was prepared by mixing $50 \mathrm{ml}$ of $2 \mathrm{mM}$ ABTS with $200 \mu \mathrm{l} 70 \mathrm{mM} \mathrm{K}_{2} \mathrm{~S}_{2} \mathrm{O}_{8}$, allowing the mixture to stand in the dark at room temperature for $16 \mathrm{~h}$ before use. The working solution was diluted to obtain an initial absorbance of AU 0.700 at $734 \mathrm{~nm}$ (M501, Camspec, United Kingdom); $100 \mu \mathrm{l}$ of the samples were mixed with $2 \mathrm{ml} \mathrm{ABTS}$ solution and absorbance was monitored for $11 \mathrm{~min}$. The results are presented as ABTS free radical scavenging activity, $\mu \mathrm{mol} \mathrm{g}^{-1}$ of fresh plant weight.

For the FRAP assay, the working reagent was prepared by mixing acetate buffer ( $300 \mathrm{mM}, \mathrm{pH} 3.6)$, a solution of $10 \mathrm{mM}$ 2,4,6-tripyridyl-s-triazine (TPTZ) in $40 \mathrm{mM} \mathrm{HCl}$, and $20 \mathrm{mM}$ $\mathrm{FeCl}_{3} \times 6 \mathrm{H}_{2} \mathrm{O}$ at 10:1:1 (v/v/v). Twenty microliters of the sample was mixed with $3 \mathrm{ml}$ of working solution and incubated in the dark for $30 \mathrm{~min}$. Then, the absorbance at $593 \mathrm{~nm}$ was read. The antioxidant power was expressed as Trolox equivalent antioxidant capacity (TEAC, $\mu$ mol Trolox per $\mathrm{g}^{-1}$ of fresh plant weight) and $\mathrm{Fe}^{2+}$ antioxidant capacity $\left(\mathrm{Fe}^{2+} \mu \mathrm{mol} \mathrm{g}-1\right.$ of fresh plant weight).

\section{Leaf Gas Exchange Indices}

Photosynthetic rate $\left(\mathrm{Pr}, \mu \mathrm{mol} \mathrm{CO} \mathrm{Cm}^{-2} \mathrm{~s}^{-1}\right)$, transpiration rate ( $\mathrm{Tr}, \mathrm{mmol} \mathrm{H}_{2} \mathrm{O} \mathrm{m} \mathrm{m}^{-2} \mathrm{~s}^{-1}$ ), and the intercellular to ambient $\mathrm{CO}_{2}$ concentration ratio $\left(C_{i} / C_{a}\right)$ were measured on the third developed leaf, using a portable photosynthesis system (LI-COR 6400XT, United States) under the conditions at $+21^{\circ} \mathrm{C}$, with a $\mathrm{CO}_{2}$ concentration of $400 \mu \mathrm{mol} \mathrm{mol} \mathrm{m}^{-1}$ and $60 \%$ relative humidity. Artificial irradiation was supplied to the leaf using different LEDs (665 and $470 \mathrm{~nm}$ ), but their respective intensities were the same for PPFD $1,000 \mu \mathrm{mol} \mathrm{m} \mathrm{m}^{-2} \mathrm{~s}^{-1}$. Photosynthesis was measured from 9 to 12 a.m.

\section{Spectral Reflectance Indices}

Spectral reflectance was measured using a leaf spectrometer (CID Bio-Science, United States) from 9 to 12 a.m. Reflection spectra obtained from the leaves were used to calculate the carotenoid reflectance index (CRI) and the anthocyanin reflectance index (ARI).
CRI, which shows carotenoid to chlorophyll ratio, was evaluated using the following formula:

$$
C R I=(1 / \rho 510)-(1 / \rho 700)
$$

ARI evaluates changes in anthocyanin amount:

$$
A R I=(1 / \rho 550)-(1 / \rho 700)
$$

where $\rho 510, \rho 550$, and $\rho 570$ represent the leaf reflectance integrated over a $10 \mathrm{~nm}$ wavelength band centered on 510, 550, and $570 \mathrm{~nm}$, respectively.

\section{Biometric Measurements}

At the end of the experiment, plant fresh mass (FW) was determined by harvesting leaves from five different plants per light treatment. Leaf area (LA) was determined using a leaf area meter (AT Delta-T Devices, United Kingdom). Dry weight (DW) was weighed after tissue dehydration at $+70^{\circ} \mathrm{C}$ for $48 \mathrm{~h}$ (Venticell-BMT, Czech Republic).

\section{Statistical Analysis}

Data were processed using the XLSTAT software (Addinsoft, France), using one-way analysis of variance, ANOVA, and Tukey's (HSD) test at confidence level $p=0.05$. Multivariate principal component analysis (PCA) was performed. The results are presented in a PCA scatterplot that indicates distinct levels of metabolites, antioxidant activity, and photosynthetic indices in lettuce subjected to constant or dynamic red and blue light at different photoperiods and a correlation circle (based on Pearson's correlation matrix) that summarizes the metabolic relations between investigated metabolites, antioxidants, and photosynthetic systems.

\section{RESULTS}

\section{The Effect of Light Conditions on Leaf Pigments, Soluble Sugars, Photosynthetic Indices and Growth Characteristics}

A parabolic PPFD profile of $16 \mathrm{~h}$ BdynRdyn $16 \mathrm{~h}$ resulted in a significant accumulation of Violax (Figure 2A) and hexoses (Fru and Glu) (Figure 2D), along with a significant decrease in pigment reflectance indexes (CRI and ARI) (Figure 2C), $C_{i} / C_{a}, \operatorname{Pr}$, and $\operatorname{Tr}$ (Figure 2E). However, the trend of Neox accumulation was similar to constant blue (BconRdyn $16 \mathrm{~h}$ ) lighting (Figure 1A). The $16 \mathrm{~h}$ photoperiod under BdynRdyn and BdynRcon treatments resulted in a significant increase of lettuce fresh weight (11.1\%) and leaf area (16.8\%) (Figure 2F). However, neither parabolic or constant PPFD patterns nor the duration of photoperiod had a significant effect on the accumulation of chlorophylls ( $\mathrm{Chl} a, \mathrm{Chl} b$ ), sucrose, or maltose (Figures 2B,D). Higher PPFD levels under a $12 \mathrm{~h}$ photoperiod (BdynRdyn $12 \mathrm{~h}$ ) significantly reduced the accumulation of neoxanthin (23.4\%), violaxanthin (19.5\%), lutein, and zeaxanthin (11.6\%). However, the total amounts of xanthophylls were similar 


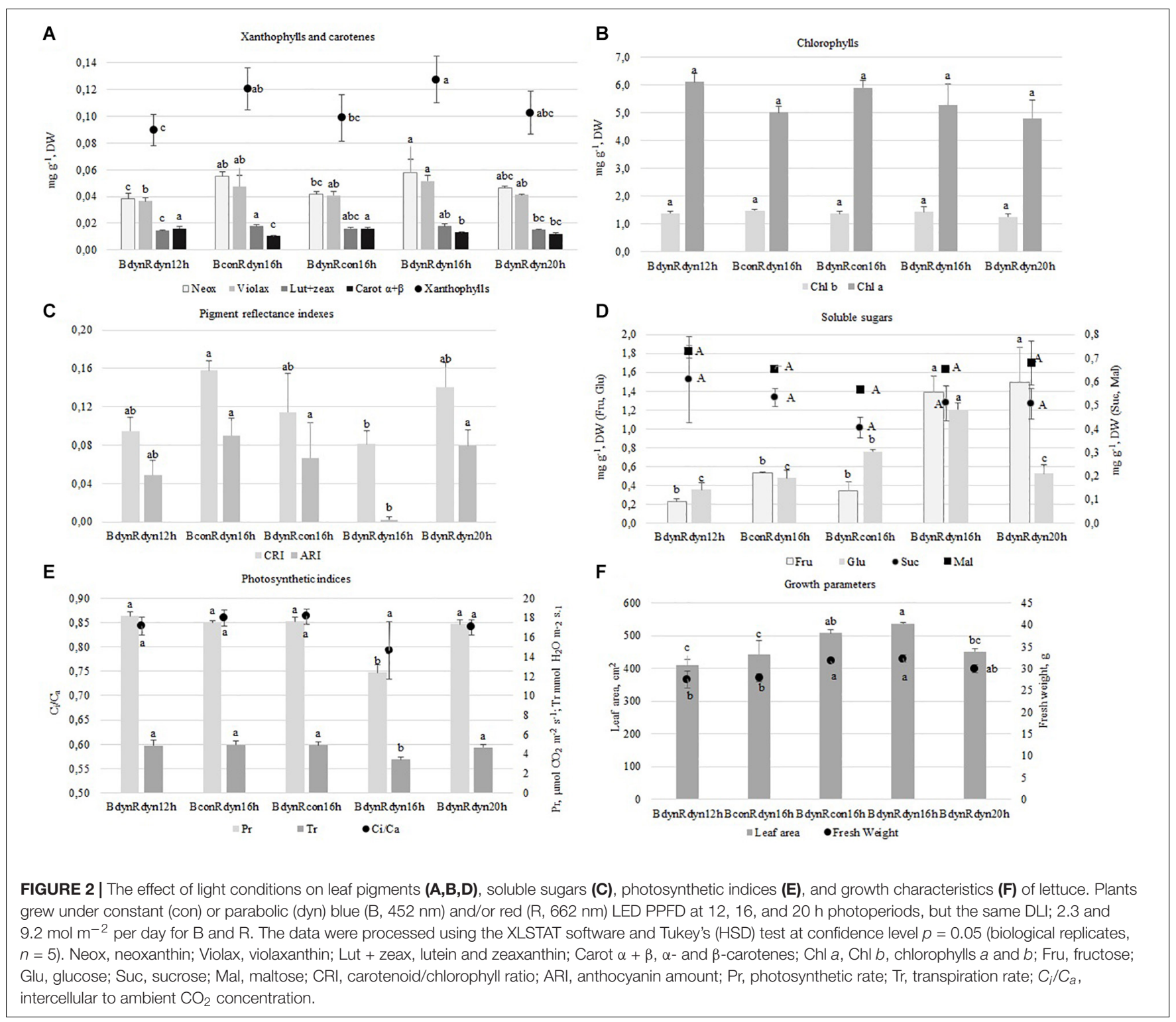

to those accumulated under lower PPFD levels under a 20 h photoperiod (BdynRdyn $20 \mathrm{~h}$ ) or under the constant red (BdynRcon $16 \mathrm{~h}$ ) PPFD treatment. Constant blue (BconRdyn $16 \mathrm{~h})$ significantly reduced $(31.0 \%)$, whereas constant red (BdynRcon $16 \mathrm{~h}$ ) significantly increased (21.9\%) the contents of $\alpha+\beta$-carotenes (Figure 2A). Under a $12 \mathrm{~h}$ photoperiod, hexose accumulated in amounts more than two times lower $\left(0.58 \mathrm{mg} \mathrm{g}^{-1} \mathrm{DW}\right)$ than sucrose, compared with other treatments (1.1-2.6 $\left.\mathrm{mg} \mathrm{g}^{-1} \mathrm{DW}\right)$ (Figure 1D).

\section{The Effect of Light Conditions on the Variation of Organic Acid Content and Antioxidant Response}

Substantial amounts of oxalic, malic, and citric acids (7.4$\left.0.5 \mathrm{mg} \mathrm{g}^{-1} \mathrm{DW}\right)$ were found in lettuce, with folic and fumaric acids present as a second major group $\left(0.19-0.05 \mathrm{mg} \mathrm{g}^{-1} \mathrm{DW}\right)$, while oxaloacetic, succinic, and ascorbic acids were present in the smallest amounts (0.034-0.003 $\mathrm{mg} \mathrm{g}^{-1} \mathrm{DW}$ ) (Figures 3A,B). The accumulation of oxalic, citric, and fumaric acids significantly (2.2 times) increased under a $12 \mathrm{~h}$ photoperiod. Constant blue (BconRdyn $16 \mathrm{~h}$ ) resulted in a significant increase in oxalic and oxaloacetic acids (2.2 times both), while parabolic blue (BdynRdyn $16 \mathrm{~h}$ ) led to a significant increase in folic acid (2.3 times). No significant differences in malic, succinic, or ascorbic acids were found.

The trends of antioxidant activity in response to lighting treatments, based on different assays, were similar (Figure 3C). Constant blue (BconRdyn $16 \mathrm{~h}$ ) light resulted in the lowest values of DPPH, ABTS ${ }^{+}$, and FRAP $(3.5,3.9$, and $8.9 \mathrm{mmol}$ TE $\left.\mathrm{g}^{-1}\right)$. Significantly, the highest antioxidant capacity was found under a $20 \mathrm{~h}$ photoperiod using the FRAP assay (12.0 mmol TE $\left.\mathrm{g}^{-1}\right)$; however, a significant decrease $(18.8 \%)$ was conditioned only under constant blue (BconRdyn $16 \mathrm{~h}$ ) treatments. The 
A

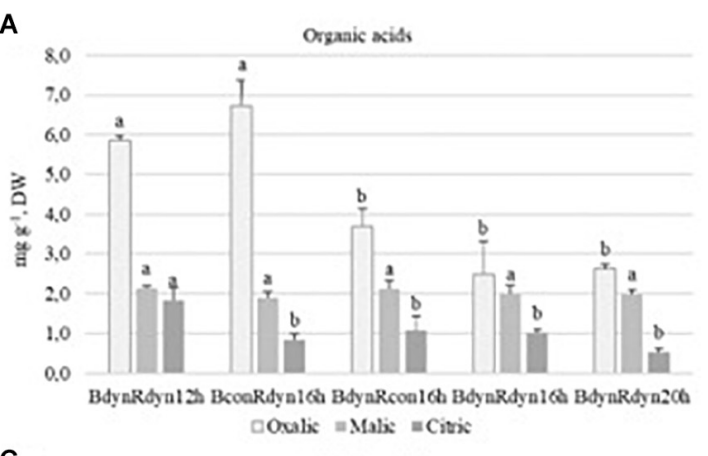

c

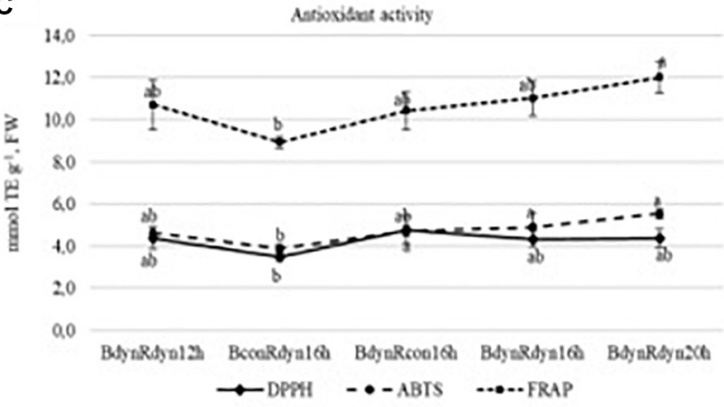

B

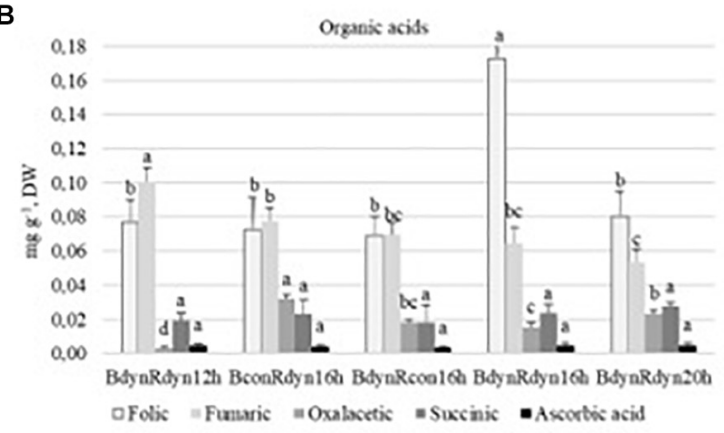

FIGURE 3 | The effect of light conditions on the variation of organic acid (A,B) content and antioxidant response with a focus on DPPH, ABTS, and FRAP assays (C) of lettuce. Plants grew under constant (con) or parabolic (dyn) blue (B, $452 \mathrm{~nm})$ and/or red (R, $662 \mathrm{~nm})$ LED PPFD at 12, 16, and $20 \mathrm{~h}$ photoperiods, but the same DLI; 2.3 and $9.2 \mathrm{~mol} \mathrm{~m}^{-2}$ per day for B and R. The data were processed using the XLSTAT software and Tukey's (HSD) test at confidence level $p=0.05$ (biological replicates, $n=5$ ).

$\mathrm{ABTS}^{+}$assay showed an antioxidant activity of $5.5 \mathrm{mmol} \mathrm{TE} \mathrm{g}^{-1}$, whereas the $\mathrm{DPPH}^{\bullet}$ assay showed no significant differences in lettuce extracts compared with the 12 - or $16 \mathrm{~h}$ parabolic blue and red light profiles (BdynRdyn).

\section{Light Affected Differences in Metabolic, Antioxidant, and Photosynthetic Response}

The PCA score scatterplot (Figure 4) shows the average coordinates of carotenes, xanthophylls, soluble sugars, organic acids, antioxidant activity, and photosynthetic indices in lettuce under constant, parabolic blue and/or red light at 12, 16, and $20 \mathrm{~h}$ photoperiods. The first two factors (F1 vs. F2) of the PCA explained 65.97 and $68.57 \%$ of the total variance in the photoperiod (Figure 4A) and lighting profile (Figure 4B) responses, respectively. F1 explained approximately $42 \%$, whereas F2 explained $24-26 \%$ of the total variability. In terms of the F1 score, the plant responses to parabolic blue and red lighting (BdynRdyn) under the 16 and $20 \mathrm{~h}$ photoperiods were clearly distinct from the responses to the $12 \mathrm{~h}$ photoperiod (Figure 4A). F1 scores from the $16 \mathrm{~h}$ photoperiods (Figure 1B) with parabolic (BdynRdyn) and constant (BconRdyn) blue light treatments were clearly distinct from those with the same photoperiod and parabolic blue and red light treatments.

The agglomerative hierarchical cluster (AHC) analysis was used to divide the responses to the light profile and photoperiod data into groups of increasing dissimilarity (Figure 5). These divisions correspond to the PCA output with the following three clusters: cluster 1 (BconRdyn $16 \mathrm{~h}$, BdynRdyn $12 \mathrm{~h}$, and BdynRcon $16 \mathrm{~h}$ ), cluster 2 (BdynRdyn $16 \mathrm{~h}$ ), and cluster 3 (BdynRdyn 20 h). Six clusters of metabolic, photosynthetic, and antioxidant responses were identified. In contrast to cluster 1, clusters 2 and 3, both groups which included parabolic blue and red light profiles (BdynRdyn) at 16 and $20 \mathrm{~h}$ photoperiods, were characterized by low $C_{i} / C_{a}$, $\operatorname{Pr}$, Tr, Chl $a, \mathrm{DPPH}$, oxalic, and fumaric acid values and low or medium malic acid, sucrose, and $\alpha$ - and $\beta$-carotene content. All analyzed metabolites were in cluster 1 or cluster 2, except for Chl $a$ (C3) and oxalic acid (C6). The highest similarity among metabolites was found in cluster 1. Fumaric acid, anthocyanin amount, violaxanthin, and neoxanthin were grouped into cluster C1-1; succinic acid, oxaloacetic acid, carotenes $\alpha+\beta$, lutein + zeaxanthin, and ascorbic acid were grouped into cluster $\mathrm{C} 1-2$; and maltose, carotenoid/chlorophyll ratio, and folic acid were grouped into cluster $\mathrm{C} 1-3$.

A negative correlation between xanthophylls (Neox, Violax, Lut + zeax) and the $12 \mathrm{~h}$ photoperiod treatment was found, with the opposite pattern for the $16 \mathrm{~h}$ photoperiod treatment. A positive correlation between photosynthetic response ( $\mathrm{Pr}$, $\operatorname{Tr}, C_{i} / C_{a}$ ) and the $12 \mathrm{~h}$ photoperiod was found (Table 1). A negative correlation between antioxidant properties (ABTS, FRAP), growth parameters (LA, FW), and the $12 \mathrm{~h}$ photoperiod was observed. A positive correlation between LA, FW, and the 16 $\mathrm{h}$ photoperiod was found. In contrast to the parabolic blue and red light profiles (BdynRdyn), a positive correlation between Pr, 
A

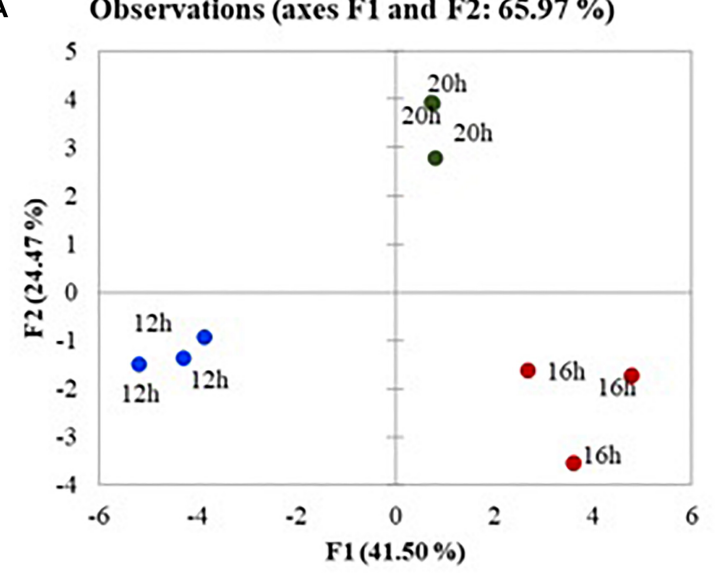

B

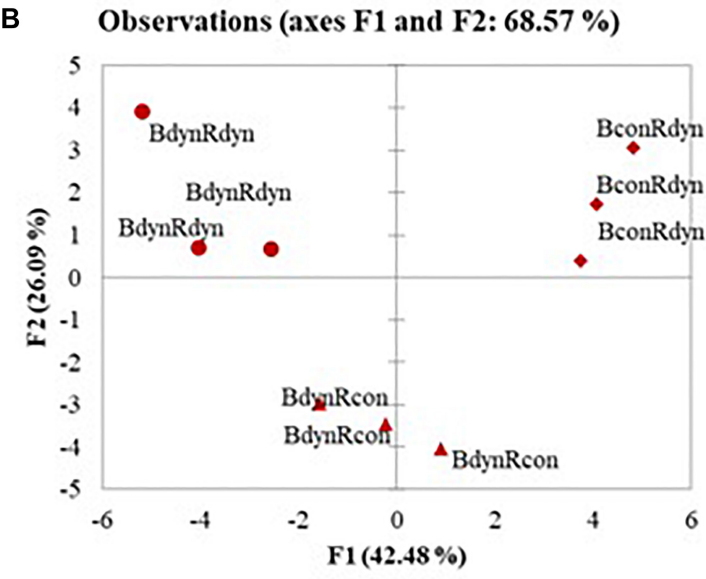

FIGURE 4 | The PCA scatterplot analysis in lettuce, indicating distinct differences in metabolites, antioxidants, and photosynthetic indices depending on lighting conditions in lettuces subjected to parabolic or constant red and blue lighting (B) at different photoperiods (A), but similar DLA. Plants grew under constant (con) or parabolic (dyn) blue (B, $452 \mathrm{~nm}$ ) and/or red (R, $662 \mathrm{~nm}$ ) LED PPFD at 12, 16, and 20 h photoperiods, but the same DLI; 2.3 and 9.2 mol $\mathrm{m}^{-2}$ per day for B and R. The data were processed using the XLSTAT software and Tukey's (HSD) test at confidence level $p=0.05$ (biological replicates, $n=5$ ).

$\operatorname{Tr}, C_{i} / C_{a}$, and constant blue light (BconRdyn) or constant red (BdynRcon) light was observed. A negative correlation between antioxidant properties (DPPH, ABTS, FRAP), growth parameters (LA, FW), and constant blue light (BconRdyn) was found, while a parabolic light profile (BdynRdyn) led to a positive correlation.

A positive correlation was found between xanthophylls (Neox, Violax, Lut + zeax) and photoperiod, with the content of these compounds increasing as the length of the light cycle increased $(12-16 \mathrm{~h})$. The opposite pattern was observed between photosynthetic response $\left(\operatorname{Pr}, \operatorname{Tr}, C_{i} / C_{a}\right)$ and photoperiod (Table 1). Similarly, antioxidant properties (ABTS, FRAP) and growth parameters (LA, FW) increased with increasing photoperiod (12-16 h). $\mathrm{Pr}, \operatorname{Tr}$, and $C_{i} / C_{a}$ increased under the constant blue (BconRdyn) or constant red (BdynRcon) light treatments compared with the other light treatments. The same was true for antioxidant properties (DPPH, ABTS, FRAP) and growth parameters (LA, FW) under the parabolic light profile BdynRdyn, with the opposite responses observed for treatments with the constant blue (BconRdyn) light profile.

\section{DISCUSSION}

\section{Photosynthetic Response and Primary Metabolism}

When plants acclimate to changing light conditions, physiological responses are the first to occur, leading to morphological, photosynthetic, and metabolic changes. Detailed knowledge about the photosynthetic pigment pool is critical for understanding the light-harvesting mechanism and photoacclimation potential of plants. The modulation and balance of photosynthetic pigment contents are part of the photosynthesis process and contribute to attaining proper equilibrium between the energy input and output (Ruban et al., 2011). Changing the photoperiod under parabolic red and blue light profiles (BdynRdyn) had a significant effect on the accumulation of neoxanthin and violaxanthin. The 12 and $16 \mathrm{~h}$ photoperiods led to a significant decrease and increase, respectively, in the xanthophyll content (Figure 2A). Although chlorophylls are the main light-capturing antennae pigments, changes in neoxanthin and violaxanthin ratio should act as a signal for light-harvesting antennae efficiency, finally resulting in acclimations to the lighting environment and lower tendencies to switch to the photoprotective mode (Gruszecki, 2010). No significant differences among chlorophylls $a$ and $b$, lutein, and zeaxanthin content were found. However, parabolic blue and red light under a $16 \mathrm{~h}$ photoperiod led to a significant decrease in the carotenoid to chlorophyll ratio (CRI). The trend of the response of carotenes and chlorophylls to all lighting conditions in this study was the same (Figures 2A-C). Thus, it can be presumed that under parabolic red and blue light profiles, the xanthophyll cycle pigments may lead to dissipation of excess energy, with carotenoids concurrently dissipating the excitation energy from chlorophyll, limiting the possible light damage to membranes.

Accumulation of soluble carbohydrates is associated with decreased photosynthesis and increased photoinhibition in the leaves (Urban and Alphonsout, 2007), and this negative feedback effect was also observed in the present study (Figures 2D,E). Apel and Hirt (2004) suggested that the inhibiting effect of soluble sugar accumulation on the Calvin cycle leads to the formation of singlet oxygen in PS II. Fanciullino et al. (2014) supposed that glucose stimulates the synthesis of carotenoids, especially xanthophylls, which are involved in the protection of photosystems against photooxidative stress. However, AHC analysis did not show any direct connections between glucose (cluster C2) and carotenoids (cluster C1) (Figure 5). It is known that glucose and fructose are primary, while sucrose and starch are the major end products of photosynthetic activity in most plants. The process of sucrose and starch formation does not depend on light because sucrose can be synthesized from glucose 


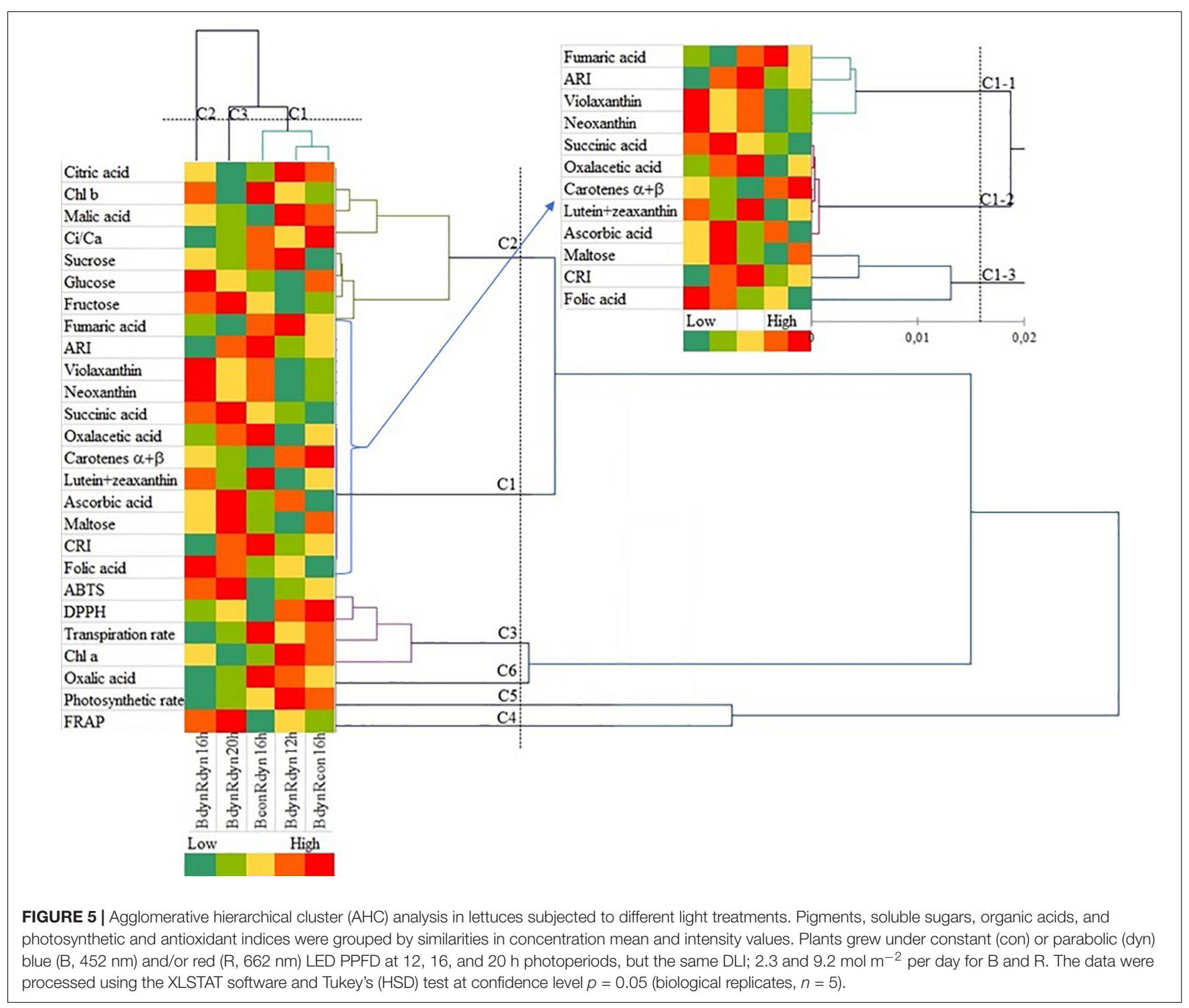

and fructose in the dark and without chlorophyll (Stein and Granot, 2019). We also obtained similar results; neither sucrose nor maltose was affected by different light profiles or photoperiod (Figure 2D), indicating that the synthesis of disaccharides is a process independent from photosynthesis. Meanwhile, AHC analysis showed a similar trend of sucrose accumulation and $C_{i} / C_{a}$, which was opposite to the trend of fructose and glucose accumulation (Figure 5). A strong negative correlation between $C_{i} / C_{a}$ and parabolic blue and red light under a $16 \mathrm{~h}$ photoperiod was found, while other light profiles or durations resulted in a weak correlation (Table 1). Thus, the stomatal behavior regulation might depend on both external environmental and internal signaling cues (Lawson and Blatt, 2014). Annunziata et al. (2017) found that the accumulation of starch in Arabidopsis grown under artificial light with a sinusoidal light profile was more intensive at the end of the day compared with that grown under constant irradiance or natural light. Parabolic lighting (BdynRdyn $16 \mathrm{~h}$ ) led to a significant increase in fructose and glucose (Figure 2D), compared with other lighting treatments, suggesting that plants avoid $\mathrm{C}$ starvation before photosynthesis starts after the dark period (Stitt and Zeeman, 2012). However, the decrease in $C_{i} / C_{a}$ resulted in a significant decrease in photosynthetic and transpiration rates (Figure 2) under a parabolic blue and red lighting treatment with a $16 \mathrm{~h}$ photoperiod (Figure 2E). McAusland et al. (2013) suggested that stomatal responses tend to be slower than photosynthetic responses, leading to suboptimal responses in stomatal conductance and photosynthetic rate, resulting in lower carbon gain. The decrease in photosynthetic rate and stomatal conductance observed over longer time scales, related to red light changes toward the end of the day, may be explained by sugar import into guard cells (Matthews et al., 2020). Sucrose transported to the guard cells is cleaved in the apoplasts to produce hexoses, which are sensed by hexokinase, which in turn signals for the stomatal closure response (Kelly et al., 2013). In contrast to that for red light, the stomatal blue light response, which has been reported to not 
require photosynthesis (Hiyama et al., 2017), is important for stomatal opening in the morning, when the irradiance spectrum is steeped in blue wavelengths. These findings suggest that light is only required for the reactions involving the primary phases of $\mathrm{CO}_{2}$ utilization during photosynthesis. Chen et al. (2019) found that a dynamic red/blue light environment had no positive effects on glucose and fructose accumulation in lettuce, in contrast to its effect on sucrose, and they also found that monochromatic lighting had the opposite effect. Our results show that hexoses were more sensitive to the lighting profile than sucrose or maltose (Figure 2D). These differences may be due to differences in DLI: the DLI was maintained at $11.54 \mathrm{~mol} \mathrm{~m}^{-2}$ per day in the current study, whereas Chen et al. (2019) used $7.49 \mathrm{~mol} \mathrm{~m}^{-2}$ per day. The highest total soluble sugar content under parabolic blue and red light was found in the $16 \mathrm{~h}$ photoperiod (BdynRdyn $16 \mathrm{~h}$ ) treatment, which showed a significantly higher fresh weight and new leaf area formation (Figures 2D,F). Other results have shown that alternating red and blue light at intervals resulted in better yield and taste. Moreover, the duration of the interval between red and blue light largely influenced the dynamics between the signal and response pathways (Chen et al., 2019).

\section{Antioxidant Response and Secondary Metabolism}

Environmental fluctuations and external stress are the main factors enhancing the antioxidant response. While most studies have indicated that red and blue components are more effective against antioxidant responses, these treatments were performed on in vitro callus cultures and only constant monochromatic spectral lights were investigated (Nazir et al., 2020; Usman et al., 2020). Nam et al. (2018) showed that blue light, compared with red or fluorescent, could be applied to enhance flavonoid levels and antioxidant activity in common buckwheat sprouts. A significant increase in antioxidant activity, based on the DPPH assay, was found in microgreens, such as red pak choi and basil, under 25 and $33 \%$ of constant blue light (Vaštakaitè et al., 2015). Son and Oh (2013) also stated that the antioxidant capacity (expressed as TEAC) of both red and green leaf lettuces grown under high ratios of blue LED (such as 59, 47 , and $35 \%$ B) was significantly higher than the lower blue to red ratio. Antioxidant activity in response to parabolic or constant light profiles was evaluated by employing antioxidant assays, mainly DPPH, ABTS, and FRAP assays. Compared with the other treatments, the lowest antioxidant activity of all the assays was recorded under constant blue and parabolic red light treatments with the $16 \mathrm{~h}$ photoperiod (Figure 3C). The increase in antioxidant capacity and induced accumulation of phenolic compounds under additional irradiation of blue LEDs in combination with red light was explained by the decreased growth of lettuce (Stutte et al., 2009; Johkan et al., 2010; Son and Oh, 2013). However, such tendencies were not observed among changes in lettuce fresh weight or leaf area (Figure 2F) and antioxidant activity (Figure 3C) in the present study.

The reason for the apparent $\mathrm{C}$ deficiency, or more specifically, the deficiency in organic acids, in plants grown under natural light is unclear (Annunziata et al., 2017). Plants adapted their $\mathrm{C}$ metabolism in response to sunny and cloudy days balancing their $\mathrm{C}$ and $\mathrm{N}$ metabolism. Sucrose signaling metabolites have been implicated in $\mathrm{C} / \mathrm{N}$ interactions through activation of phosphoenolpyruvate carboxylase and nitrate reductase and increased anaplerotic flux of C into organic acids (Figueroa et al., 2016). However, sucrose did not differ significantly (Figure 2D) between lighting treatments; moreover, AHC analysis did not show any similarities with organic acids, except for malic and citric acids (Figure 5). The changes in organic acid content (Figures 3A,B) suggest that metabolism of organic acids may be less robust to changes in light intensity

TABLE 1 | Correlation between photosynthetic indices, antioxidant activity, growth parameters, and lighting conditions.

\begin{tabular}{|c|c|c|c|c|c|c|}
\hline & \multicolumn{3}{|c|}{ BdynRdyn } & \multicolumn{3}{|c|}{$16 \mathrm{~h}$} \\
\hline & $12 \mathrm{~h}$ & $16 \mathrm{~h}$ & $20 \mathrm{~h}$ & BconRdyn & BdynRcon & BdynRdyn \\
\hline Violax & $-0.701^{\star}$ & $0.899^{*}$ & -0.199 & 0.098 & $-0.664^{\star}$ & $0.567^{\star}$ \\
\hline Lut + zeax & $-0.475^{\star}$ & $0.831^{\star}$ & -0.356 & 0.365 & $-0.589^{\star}$ & 0.223 \\
\hline Chla & $0.683^{*}$ & -0.099 & -0.584 & $-0.513^{\star}$ & $0.663^{\star}$ & -0.150 \\
\hline $\operatorname{Pr}$ & $0.600^{*}$ & $-0.973^{\star}$ & 0.373 & $0.470^{\star}$ & $0.513^{\star}$ & $-0.982^{*}$ \\
\hline $\operatorname{Tr}$ & $0.544^{*}$ & $-0.878^{\star}$ & 0.335 & $0.478^{\star}$ & $0.458^{\star}$ & $-0.935^{\star}$ \\
\hline$C_{i} / C_{a}$ & $0.329^{*}$ & $-0.611^{*}$ & 0.282 & $0.344^{*}$ & $0.391^{*}$ & $-0.734^{\star}$ \\
\hline DPPH & 0.019 & -0.022 & 0.003 & $-0.772^{\star}$ & $0.622^{*}$ & 0.150 \\
\hline ABTS & $-0.538^{\star}$ & -0.163 & 0.701 & $-0.782^{\star}$ & 0.277 & $0.505^{\star}$ \\
\hline FRAP & $-0.403^{\star}$ & -0.163 & 0.566 & $-0.798^{\star}$ & 0.195 & $0.603^{*}$ \\
\hline
\end{tabular}

Correlation coefficient ( $r$ ) for the pairs of investigated parameters ( $n=3$ for each parameter) is presented. Correlations marked with asterisk mark $\left.{ }^{*}\right)$ are significant at $p<0.05$. B, blue, $452 \mathrm{~nm}$; R, red, $662 \mathrm{~nm}$; dyn, parabolic profile; con, constant profile; Neox, neoxanthin; Violax, violaxanthin; Lut + zeax, lutein and zeaxanthin; Chl a, $\mathrm{Chl} b$, chlorophylls a and b; $\mathrm{Pr}$, photosynthetic rate; $\mathrm{Tr}$, transpiration rate; $C_{i} / C_{a}$, intercellular to ambient $\mathrm{CO}_{2}$ concentration; $L A$, leaf area; $F W$, fresh weight. 
profiles than to photoperiod. Ascorbic acid is involved in many plant physiological processes, including photosynthesis or transmembrane electron transport (Plumb et al., 2018). In agreement, AHC analysis showed close similarity among ascorbic acid, lutein, zeaxanthin, and carotenes (cluster C1-2) (Figure 5). On the other hand, neither parabolic nor constant lighting profiles or different photoperiods (it should be stated that DLI was the same in all treatments) had a significant effect on ascorbic acid accumulation (Figure 3B). A significant increase in ascorbic acid was mainly obtained by extending the continuous light for 48 (Zhou et al., 2012) or 72 h (Yabuta et al., 2007). Moreover, in agreement with Yabuta et al. (2007), the dissimilarity among hexoses, sucrose (cluster C2), and ascorbic acid (cluster C1) (Figure 5) shows that photosynthetic electron transport in chloroplasts is highly related to ascorbic acid pool size regulation in the leaves but is independent of sugars.

\section{CONCLUSION}

The results obtained and the PCA analysis confirmed the significant impact of both photoperiod and the parabolic profiles of PPFD distribution on lettuce physiological response. A $16 \mathrm{~h}$ photoperiod resulted in significantly higher xanthophyll content (neoxanthin, violaxanthin, lutein, and zeaxanthin) in lettuce leaves under both constant and parabolic blue light treatments (BconRdyn 16 h; BdynRdyn 16 h). Lower and higher PPFD levels under a 20 and $12 \mathrm{~h}$ photoperiod (BdynRdyn $20 \mathrm{~h}$, BdynRdyn $12 \mathrm{~h}$ ), respectively, and maintaining the same DLI had a pronounced reducing impact on photosynthetic indices $(\mathrm{Pr}$, $\left.\operatorname{Tr}, C_{i} / C_{a}\right)$, xanthophylls, soluble sugar contents, and antioxidant properties of lettuce leaves. Parabolic lighting (BdynRdyn $16 \mathrm{~h}$ ) led to a significant decrease in $C_{i} / C_{a}$, resulting in decreased photosynthetic and transpiration rates, compared with constant blue or red light PPFD over the same photoperiod (BconRdyn,

\section{REFERENCES}

Annunziata, M. G., Aplet, F., Carillo, P., Krause, U., Feil, R., Mengin, V., et al. (2017). Getting back to nature: a reality check for experiments in controlled environments. J. Exp. Bot. 68, 4463-4477.doi: 10.1093/jxb/erx220

Apel, K., and Hirt, H. (2004). Reactive oxygen species: metabolism, oxidative stress, and signal transduction. Annu. Rev. Plant Biol. 55, 373-399.doi: 10.1146/ annurev.arplant.55.031903.141701

Bantis, F., Smirnakou, S., Ouzounis, T., Koukounaras, A., Ntagkas, N., and Radoglou, K. (2018). Current status and recent achievements in the field of horticulture with the use of light-emitting diodes (LEDs). Sci. Hort. 235, 437-451.doi: 10.1016/j.scienta.2018.02.058

Brons, C., and Olieman, C. (1983). Study of the high-performance liquid chromatographic separation of reducing sugars, applied to the determination of lactose in milk. J. Chromatogr. 259, 79-86.doi: 10.1016/S0021-9673(01)87980-2

Chen, X.-L., Wang, L.-C., Li, T., Yang, Q.-C., and Guo, W.-Z. (2019). Sugar accumulation and growth of lettuce exposed to different lighting modes of red and blue LED light. Sci. Rep 9:969. doi: 10.1038/s41598-019-43498-8

Chernys, J. T., and Zeevaart, J. A. D. (2000). Characterization of the 9cisepoxycarotenoid dioxygenase gene family and the regulation of abscisic acid biosynthesis in avocado. Plant Physiol. 124, 343-353.doi: 10.1104/pp.124.1.343

Dietz, K.-J. (2015). Efficient high light acclimation involves rapid processes at multiple mechanistic levels. J. Exp. Bot. 66, 2401-2414.doi: 10.1093/jxb/eru505
BdynRcon at $16 \mathrm{~h}$ ). Moreover, under constant blue lighting, higher carotenes $\alpha+\beta$, anthocyanin (ARI) content, and CRI were obtained, but these were accompanied by decreased biomass accumulation and antioxidant activity.

\section{DATA AVAILABILITY STATEMENT}

The original contributions presented in the study are included in the article/supplementary material, further inquiries can be directed to the corresponding author/s.

\section{AUTHOR CONTRIBUTIONS}

GS: data analysis, writing of the manuscript. AV: joint coordination of the experiment, modeling of light parameters, and data summarizing JM: spectrophotometric analysis, biometric measurements, and data summarizing. $\mathrm{PH}$ : chromatographic analysis. KL: photosynthesis and optical indices measurements, data summarizing. $\mathrm{AB}$ and $\mathrm{PD}$ : the realization of lighting schedules in vegetative experiments, data analysis All authors read and approved the final version of the manuscript.

\section{FUNDING}

This research was funded by a grant (No. S-MIP-17-23) from the Research Council of Lithuania.

\section{ACKNOWLEDGMENTS}

We would like to thank Editage (www.editage.com) for English language editing.

Dong, C., Fu, Y., Liu, G., and Liu, H. (2014). Growth, photosynthetic characteristics, antioxidant capacity and biomass yield and quality of wheat (Triticum aestivum L.) exposed to LED light sources with different spectra combinations. J. Agron. Crop Sci. 200, 219-230.doi: 10.1111/jac.12059

Edelenbos, M., Christensen, L. P., and Grevsen, K. (2001). HPLC determination of chlorophyll and carotenoid pigments in processed green pea cultivars (Pisum sativum L.). J. Agric. Food Chem. 49, 4768-4774.doi: 10.1021/jf010569z

Fanciullino, A. L., Bidel, L. P. R., and Urban, L. (2014). Carotenoid responses to environmental stimuli: integrating redox and carbon controls into a fruit model. Plant Cell Environ. 37, 273-289.doi: 10.1111/pce.12153

Figueroa, C. M., Feil, R., Ishihara, H., Watanabe, M., Kölling, K., Krause, U., et al. (2016). Trehalose 6-phosphate coordinates organic and amino acid metabolism with carbon availability. Plant J. 85, 410-423.doi: 10.1111/tpj.13114

García-Plazaola, J., Esteban, R., Fernández-Marín, B., Kranner, I., and PorcarCastell, A. (2012). Thermal energy dissipation and xanthophyll cycles beyond the Arabidopsis model. Photosynth. Res. 113, 89-103.doi: 10.1007/s11120-0129760-7

Gruszecki, W. I. (2010). Light-driven regulatory mechanisms in the photosynthetic antenna complex LHCII. Biochem. Soc. Trans. 38, 702-704.doi: 10.1042/ bst0380702

Hasan, M. M., Bashir, T., Ghosh, R., Lee, S. K., and Bae, H. (2017). An overview of LEDs' effects on the production of bioactive compounds and crop quality. Molecules. 22:1420.doi: 10.3390/molecules22091420 
Häusler, R. E., Heinrichs, L., Schmitz, J., and Flügge, U. I. (2014). How sugars might coordinate chloroplast and nuclear gene expression during acclimation to high light intensities. Mol. Plant. 7, 1121-1137.doi: 10.1093/mp/ssu064

Hiyama, A., Takemiya, A., Munemasa, S., Okuma, E., Sugiyama, N., Tada, Y., et al. (2017). Blue light and $\mathrm{CO}_{2}$ signals converge to regulate light-induced stomatal opening. Nat. Commun. 8:1284. doi: 10.1038/s41467-017-01237-5

Johkan, M., Shoji, K., Goto, F., Hashida, S., and Yoshihara, T. (2010). Blue lightemitting diode light irradiation of seedlings improves seedling quality and growth after transplanting in red leaf lettuce. HortScience 45, 1809-1814.doi: 10.21273/HORTSCI.45.12.1809

Johnson, M. P. (2016). Photosynthesis. Essays Biochem. 60, 255-273. doi: 10.1042/ EBC20160016

Kelly, G., Moshelion, M., David-Schwartz, R., Halperin, O., Wallach, R., Attia, Z., et al. (2013). Hexokinase mediates stomatal closure. Plant J. 75, 977-988.doi: $10.1111 /$ tpj. 12258

Kraujalyte, V., Venskutonis, P. R., Pukalskas, A., Česonienė, L., and Daubaras, R. (2013). Antioxidant properties and polyphenolic compositions of fruits from different European cranberrybush (ViburnuB opulus L.) genotypes. Food Chem. 141, 3695-3702.doi: 10.1016/j.foodchem.2013.06.054

Lawson, T., and Blatt, M. R. (2014). Stomatal size, speed, and responsiveness impact on photosynthesis and water use efficiency. Plant Physiol. 164, 1556-1570.doi: 10.1104/pp.114.237107

Lee, M. K., Arasu, M. V., Park, S., Byeon, D. H., Chung, S. O., Park, S. U., et al. (2016). LED lights enhance metabolites and antioxidants in Chinese cabbage and kale. Braz. Arch. Biol. Technol. 59:e16150546. doi: 10.1590/1678-43242016150546

Lekkham, P., Srilaong, V., Pongprasert, N., and Kondo, S. (2016). Anthocyanin concentration and antioxidant activity in light-emitting diode (LED)-treated apples in a greenhouse environmental control system. Fruits 71, 269-274.doi: $10.1051 /$ fruits/2016022

Ma, C., Sun, Z., Chen, C., Zhang, L., and Zhu, S. (2014). Simultaneous separation and determination of fructose, sorbitol, glucose and sucrose in fruits by HPLCELSD. Food Chem. 145, 784-788.doi: 10.1016/j.foodchem.2013.08.135

Matthews, J. S. A., Vialet-Chabrand, S., and Lawson, T. (2020). Role of blue and red light in stomatal dynamic behaviour. J. Exp. Bot. 71, 2253-2269.doi: 10.1093/ jxb/erz563

McAusland, L., Davey, P. A., Kanwal, N., Baker, N. R., and Lawson, T. (2013). A novel system for spatial and temporal imaging of intrinsic plant water use efficiency. J. Exp. Bot. 64, 4993-5007.doi: 10.1093/jxb/ert288

Moore, B., Zhou, L., Rolland, F., Hall, Q., Cheng, W.-H., Liu, Y.-X., et al. (2003). Role of the Arabidopsis glucose sensor HXK1 in nutrient, light, and hormonal signaling. Science 300, 332-336.doi: 10.1126/science.1080585

Mozzo, M., Dall'Osto, L., Hienerwadel, R., Bassi, R., and Croce, R. (2008). Photoprotection in the antenna complexes of Photosystem II: role of individual xanthophylls in chlorophyll triplet quenching. J. Biol. Chem. 283, 6184-6192. doi: 10.1074/jbc.M708961200

Nam, T. G., Dae-Ok, K., and Seok, H. E. (2018). Effects of light sources on major flavonoids and antioxidant activity in common buckwheat sprouts. Food Sci. Biotechnol. 27, 169-176.doi: 10.1007/s10068-017-0204-1

Nazir, M., Ullah, M. A., Younas, M., Siddiquah, A., Shah, M., Giglioli-Guivarc'h, N., et al. (2020). Light-mediated biosynthesis of phenylpropanoid metabolites and antioxidant potential in callus cultures of purple basil (Ocimum basilicum L. var purpurascens). Plant Cell Tissue Organ. Cult. 142, 107-120.doi: 10.1007/ s11240-020-01844-Z

Plumb, W., Townsend, A. J., Rasool, B., Alomrani, S., Razak, N., Karpinska, B., et al. (2018). Ascorbate-mediated regulation of growth, photoprotection and photoinhibition in Arabidopsis thaliana. J. Exp. Bot. 69, 2823-2835.doi: 10. 1093/jxb/ery170

Robert, B., Horton, P., Pascal, A. A., and Ruban, A. V. (2004). Insights into the molecular dynamics of plant light-harvesting proteins in vivo. Trends Plant Sci. 9, 385-390.doi: 10.1016/j.tplants.2004.06.006

Ruban, A. V., Johnson, M. P., and Duffy, C. D. P. (2011). Natural light harvesting: principles and environmental trends. Energ. Environ. Sci. 4, 1643-1650.doi: 10.1039/C0EE00578A
Sabzalian, M. R., Heydarizadeh, P., Zahedi, M., Boroomand, A., Agharokh, M., Sahba, M. R., et al. (2014). High performance of vegetables, flowers, and medicinal plants in a red-blue LED incubator for indoor plant production. Agron. Sustain. Dev. 34, 879-886.doi: 10.1007/s13593-014-0209-6

Samuolienè, G., Brazaitytè, A., Sirtautas, R., Viršilè, A., Sakalauskaitė, J., Sakalauskienè, S., et al. (2013). LED illumination affects bioactive compounds in romaine baby leaf lettuce. J. Sci. Food Agric. 93, 3286-3291.doi: 10.1002/jsfa. 6173

Samuolienè, G., Sirtautas, R., Brazaitytè, A., and Duchovskis, P. (2012). LED lighting and seasonality effects antioxidant properties of baby leaf lettuce. Food Chem. 134, 1494-1499.doi: 10.1016/j.foodchem.2012.03.061

Samuolienè, G., Viršilè, A., Haimi, P., and Miliauskienè, J. (2020). Photoresponse to different lighting strategies during red leaf lettuce growth. J. Photochem. Photobiol. B Biol. 202, 111726.doi: 10.1016/j.jphotobiol.2019.111726

Shen, Y. Z., Guo, S. S., Ai, W. D., and Tang, Y. K. (2014). Effects of illuminants and illumination time on lettuce growth, yield and nutritional quality in a controlled environment. Life Sci. Space Res. 2, 38-42. doi: 10.1016/j.1ssr.2014.06.001

Son, K.-H., and Oh, M.-M. (2013). Leaf shape, growth, and antioxidant phenolic compounds of two lettuce cultivars grown under various combinations of blue and red light-emitting diodes. HortScience 48, 988-995.doi: 10.21273/ HORTSCI.48.8.988

Stein, O., and Granot, D. (2019). An overview of sucrose synthases in plants. Front. Plant Sci. 10:95. doi: 10.3389/fpls.2019.00095

Stitt, M., and Zeeman, S. C. (2012). Starch turnover: pathways, regulation and role in growth. Cur. Opin. Plant Biol. 15, 282-292. doi: 10.1016/j.pbi.2012. 03.016

Stutte, G. W., Edney, S., and Skerritt, T. (2009). Photoregulation of bioprotectant content of red leaf lettuce with light-emitting diodes. HortScience 44, 79-82.doi: 10.21273/HORTSCI.44.1.79

Urban, L., and Alphonsout, L. (2007). Girdling decreases photosynthetic electron fluxes and induces sustained photoprotection in mango leaves. Tree Physiol. 27, 345-352.doi: 10.1093/treephys/27.3.345

Usman, H., Ullah, M. A., Jan, H., Siddiquah, A., Drouet, S., Anjum, S., et al. (2020). Interactive effects of wide-spectrum monochromatic lights on phytochemical production, antioxidant and biological activities of Solanum xanthocarpum callus cultures. Molecules 25:2201.doi: 10.3390/molecules25092201

Vaštakaitè, V., Viršilè, A., Brazaitytė, A., Samuolienè, G., Jankauskienė, J., Sirtautas, R., et al. (2015). The effect of blue light dosage on growth and antioxidant properties of microgreens. Sodinink. Daržinink. 34, 25-35.

Wang, Y., Wang, J., Chang, W., Zhao, Z., and Cao, J. (2014). HPLC method for the simultaneous quantification of the major organic acids in Angeleno plum fruit. IOP Conf. Ser. Mater. Sci. Eng. 62:012035. doi: 10.1088/1757-899X/62/1/012035

Yabuta, Y., Mieda, T., Rapolu, M., Nakamura, A., Motoki, T., Maruta, T., et al. (2007). Light regulation of ascorbate biosynthesis is dependent on the photosynthetic electron transport chain but independent of sugars in Arabidopsis. J. Exp. Bot. 58, 2661-2671.doi: 10.1093/jxb/erm124

Zhou, W. L., Liu, W. K., and Yang, Q. C. (2012). Quality changes in hydroponic lettuce grown under pre-harvest short-duration continuous light of different intensities. J. Hortic. Sci. Biotechnol. 87, 429-434. doi: 10.1080/14620316.2012. 11512890

Conflict of Interest: The authors declare that the research was conducted in the absence of any commercial or financial relationships that could be construed as a potential conflict of interest.

Copyright (c) 2021 Samuolienè, Viršilè, Miliauskienè, Haimi, Laužikè, Brazaitytè and Duchovskis. This is an open-access article distributed under the terms of the Creative Commons Attribution License (CC BY). The use, distribution or reproduction in other forums is permitted, provided the original author(s) and the copyright owner(s) are credited and that the original publication in this journal is cited, in accordance with accepted academic practice. No use, distribution or reproduction is permitted which does not comply with these terms. 